
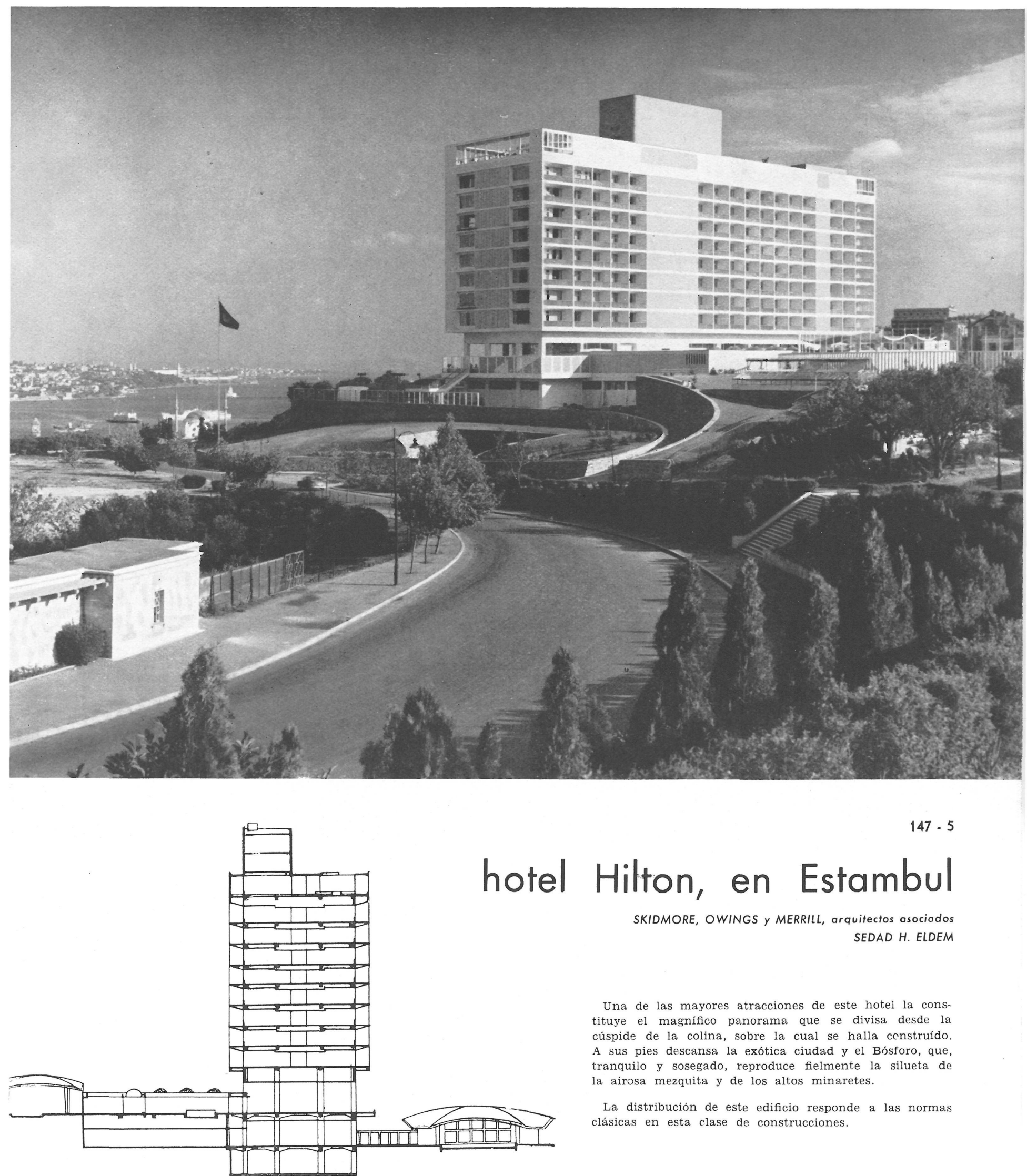

$147 \cdot 5$

\title{
hotel Hilton, en Estambul
}

SKIDMORE, OWINGS y MERRILL, arquitectos asociodos

SEDAD H. ELDEM 

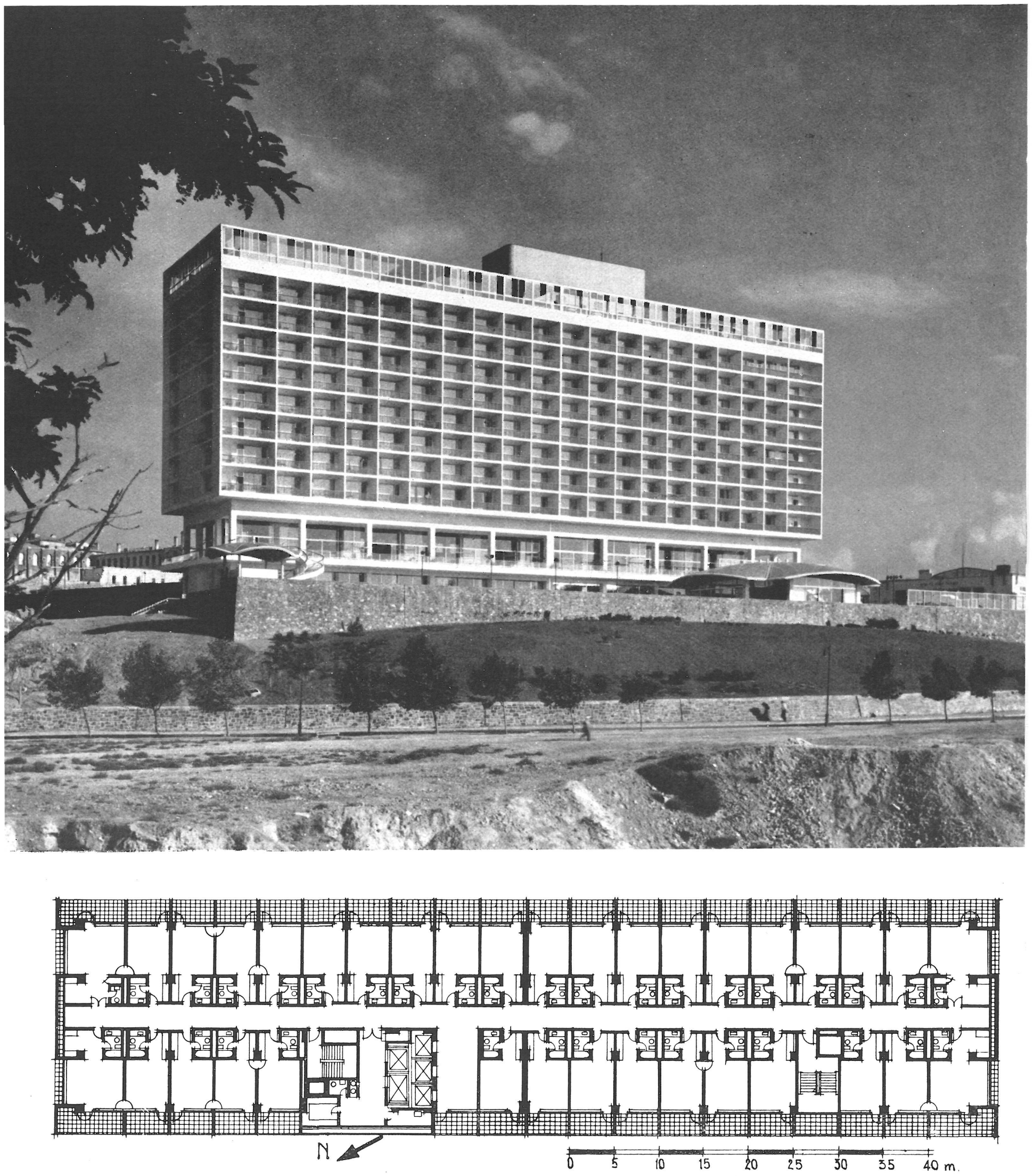


\section{Gerramiento}
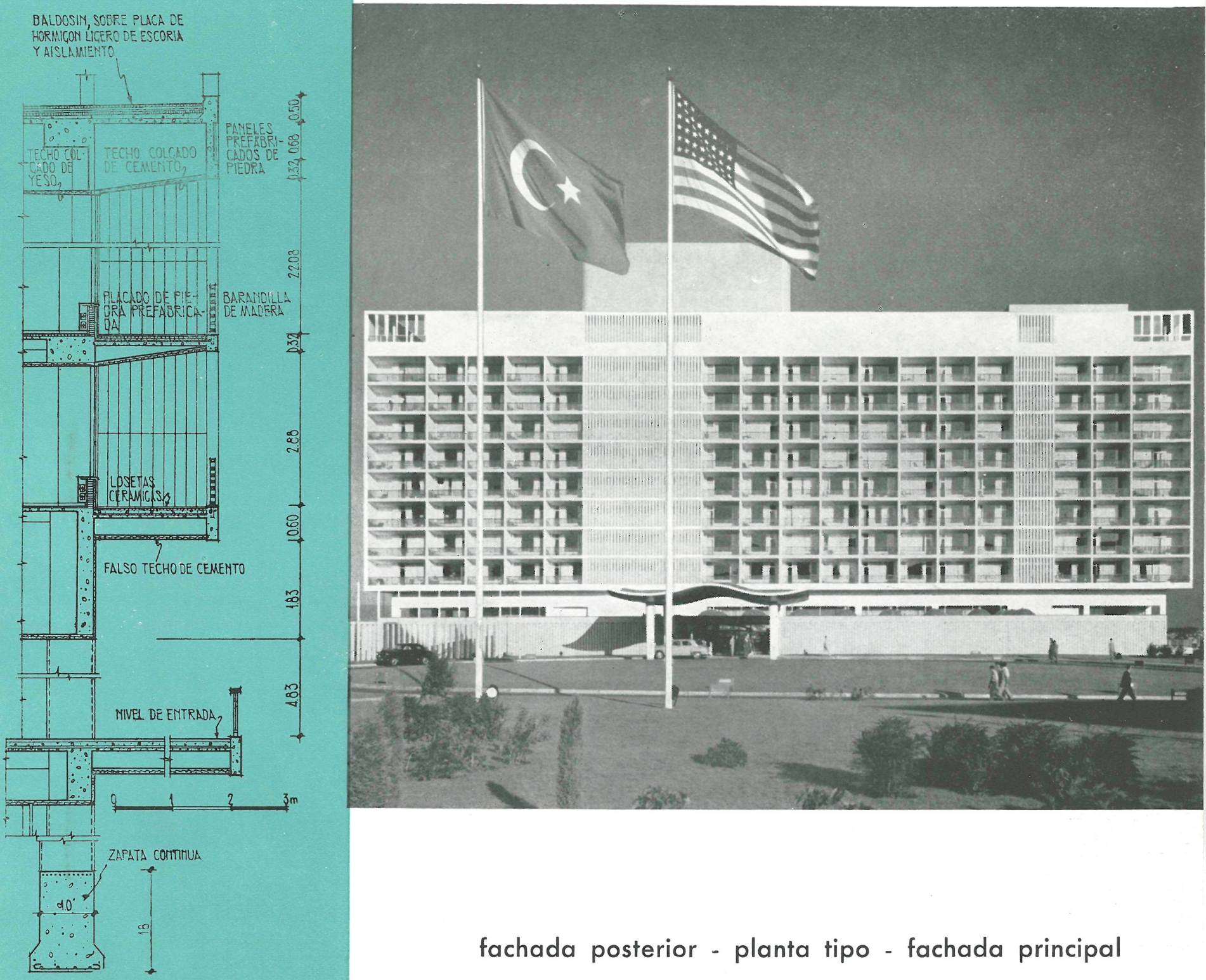

fachada posterior - planta tipo - fachada principal

En la planta noble, se distribuye la zona representativa: vestíbulos, salones, tiendas...; una entreplanta alberga los servicios, y, sobre ellas, una serie de plantas iguales, de corredor central y habitaciones a fachada, se destinan a los huéspedes. Cada dormitorio se trasluce al exterior de forma patente y sincera, respondiendo a una modulación en alzado, cuyo resultado es la retícula que forman las terrazas, interrumpida tan sólo por las bandas verticales en celosía de las comunicaciones verticales: escaleras y ascensores.

La estructura general es de hormigón armado, con miras a economizar acero en lo posible. Las vigas transversales resultan francamente pesadas y de canto muy alto, lo cual puede explicarse no sólo por la economía pretendida y antes mencionada, sino para prevenirse contra posibles movimientos sísmicos. 

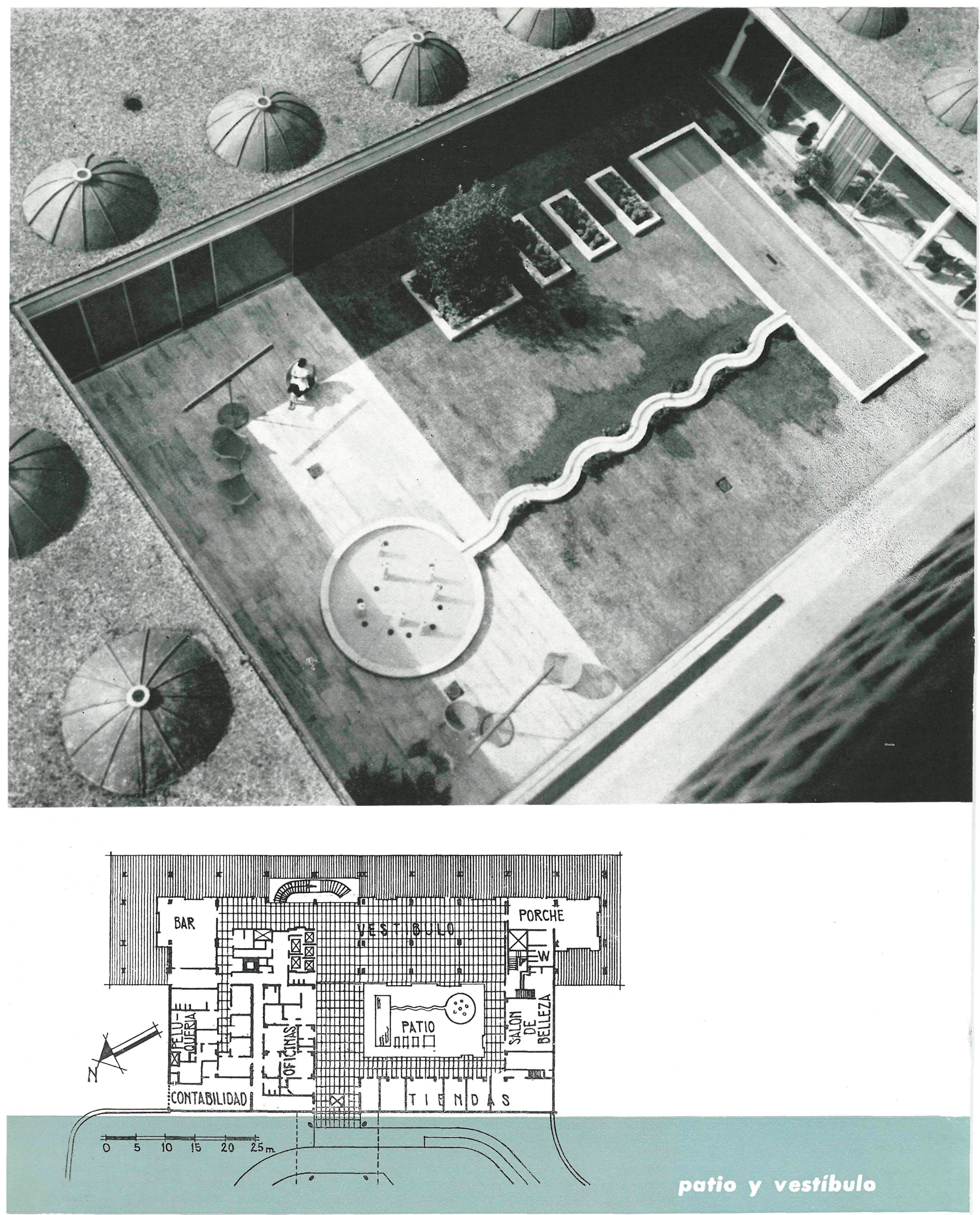


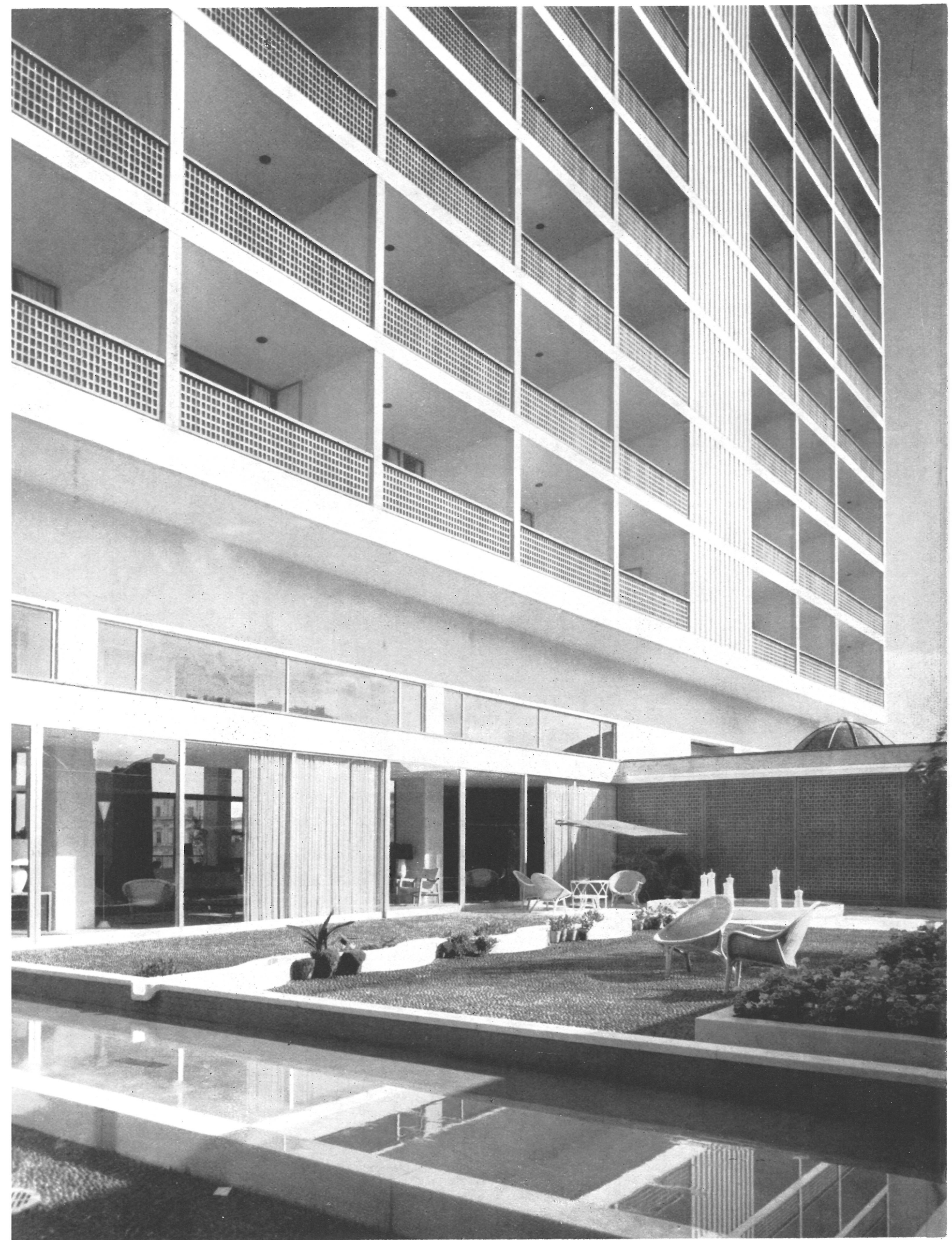




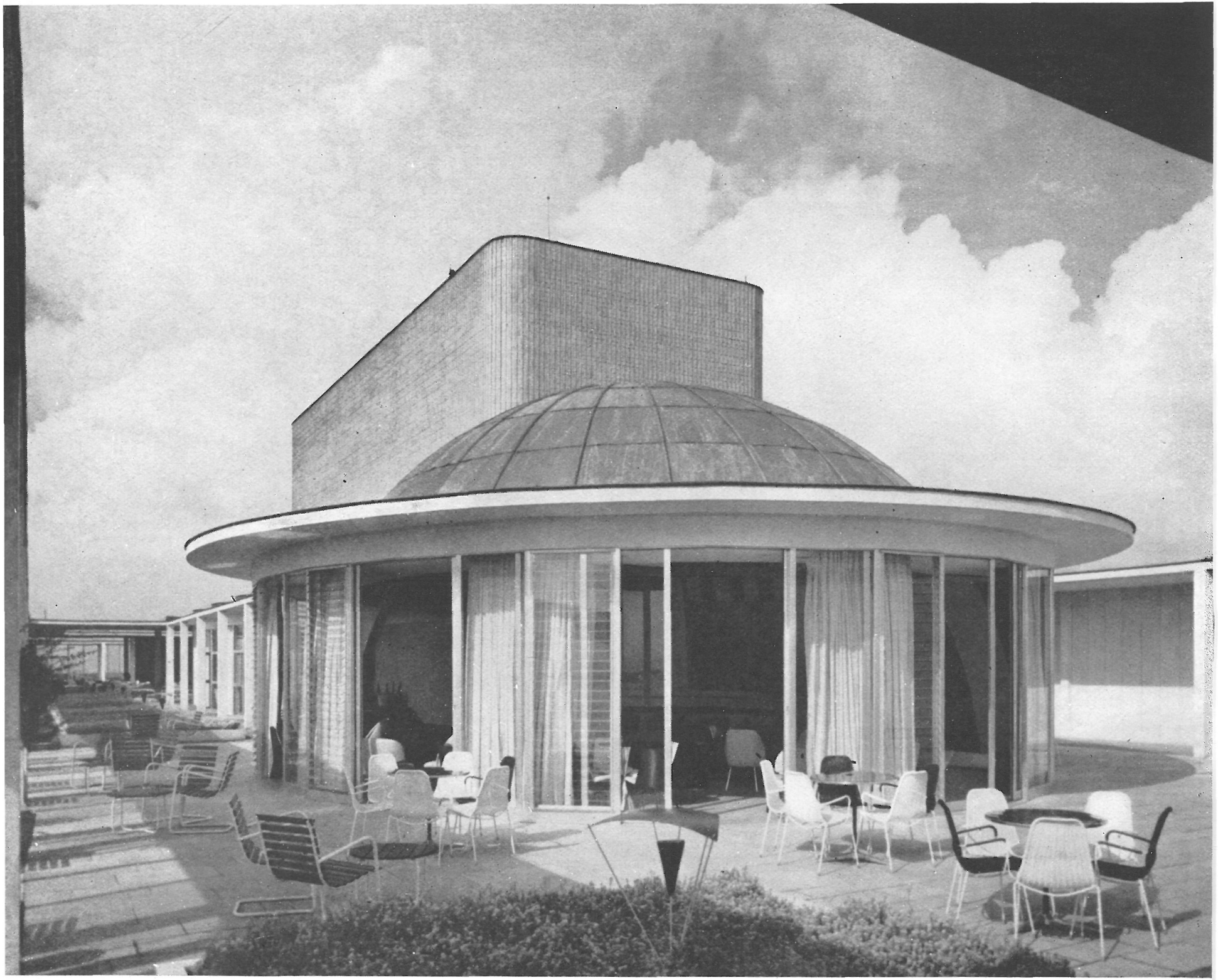

Belvedere, terraza $\mathrm{y}$ templete de ligero y modernizado sabor moruno.

Parece extraño que, en un edificio de lujo, se emplee la palabra economía tan insistentemente, pero ello obedece a ia escasa calidad de la mano de obra y la necesidad de importarla, así como muchos materiales.

Naturalmente, la decoración interior la adaptación del terreno circundante: terrazas, espacios verdes, lugares de paseo, belvederes..., son francamente acertados. Así, se han dispuesto rincones de aspecto variado, como el patio de sabor moruno que da al vestíbulo, cuya fuente, de cauce serpenteante, produce un sonido bien temperado, tradicional en la sensibilidad del árabe; la terraza con que se remata el edificio protegida de los vientos por una lonja acristalada; la piscina, próxima al co- medor, ofrece un panorama sedante; la portada principal, con su placa ondulada de hormigón, pintada de oro, recuerda la anecdótica «alfombra voladoray, $y$, por fin, el escalonamiento de jardines, que conduce a la ciudad, permitiendo destacar, vibrante, la masa clara del edificio.

V. M. 


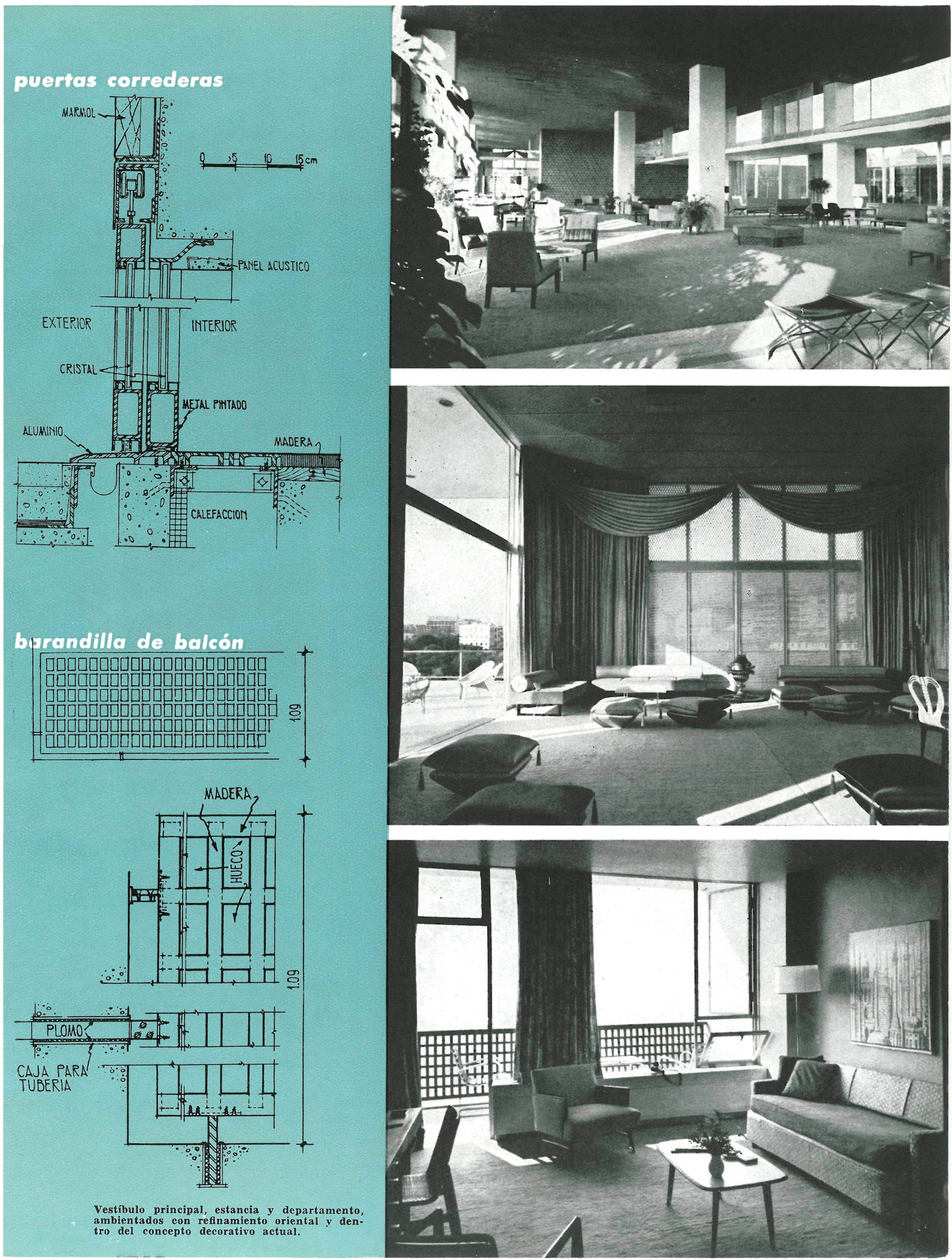

